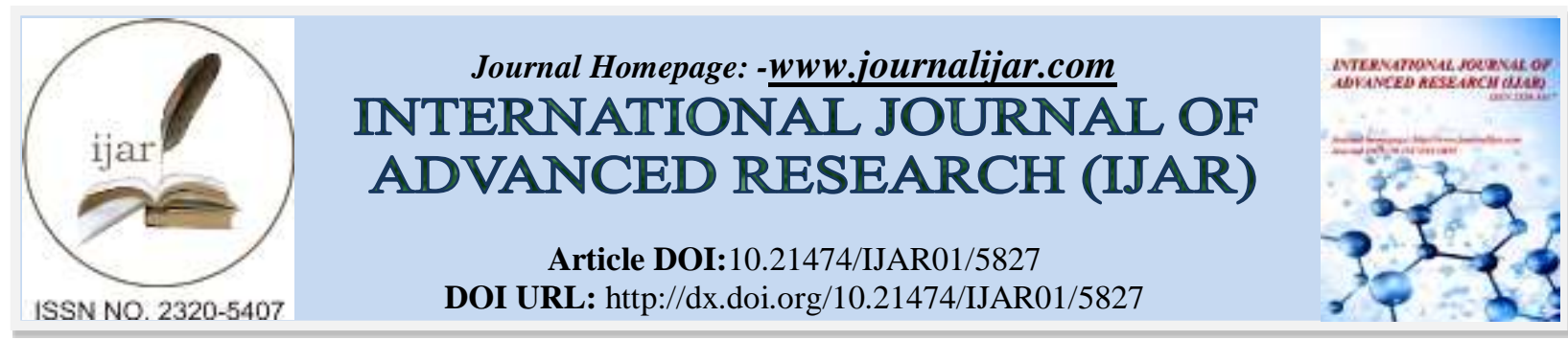

RESEARCH ARTICLE

\title{
INHIBITORY EFFECT OF THE ACETONE EXTRACT OF MAIZE LEAVES ON THE MYCELIAL GROWTH OF ASPERGILLUS PARASITICUS ALONG WITH ITS AFLATOXINS PRODUCTION.
}

\author{
Maneesh Kumar ${ }^{1,2 *}$, Harish Kumar ${ }^{1}$, Roshan Kamal Topno ${ }^{3}$, Ganesh Chandra Sahoo ${ }^{2}$, Subham Kumar ${ }^{1}$, \\ Kundan Kumar ${ }^{1}$, Siddharth Jha ${ }^{1}$ and Sushil Kumar ${ }^{4}$. \\ 1. Department of Biotechnology, College of Commerce, Arts and Science (Magadh University, Bodh Gaya), \\ Patna-800020, Bihar, India. \\ 2. Department of Virology, Rajendra Memorial Research Institute of Medical Sciences (ICMR), Agamkuan, \\ Patna-800007, Bihar, India. \\ 3. Department of Epidemiology, Rajendra Memorial Research Institute of Medical Sciences (ICMR), Agamkuan, \\ Patna-800007, Bihar, India. \\ 4. Department of Pathology, NIMS University, Jaipur, Rajasthan, India.
}

\section{Manuscript Info}

Manuscript History

Received: 10 September 2017

Final Accepted: 12 October 2017

Published: November 2017

Key words:-

Aspergillus parasiticus,

Phytoconstituents, Aflatoxins, Maize, Anti-aflatoxigenic.

\begin{abstract}
This study shows the anti-fungal and anti-aflatoxigenic activities of acetone extract of Maize leaves. As contamination caused by Aspergillus parasiticus and aflatoxin is a major challenge in agriculture and food industry, we tried to inhibit the mycelial growth of $A$. parasiticus and aflatoxins production. Here, we investigated the effect of acetone extract of hybrid stain of maize leaves (Malviya Hybrid Makka) on the growth of $A$. parasiticus and aflatoxin production. Phytochemical screening of this extract was also carried out which revealed the presence of many anti-fungal and anti-aflatoxigenic compounds such as proteins, carbohydrates, flavonoids and terpenes. The extract showed $82.89 \%$ inhibition of the growth of A. parasiticus mycelial and $100 \%$ inhibition of the aflatoxins production at the concentration of $250 \mu \mathrm{l} / \mathrm{ml}$ and $200 \mu \mathrm{l} / \mathrm{ml}$ respectively. TLC method was used for qualitative and quantitative analysis of the aflatoxins that revealed the bands of aflatoxin B1, B2, G1 and G2, and indicated that B1 is found in higher concentration than other aflatoxins. The overall study indicates that acetone extract of Maize leaves possess good potential to arrest the growth of A. parasiticus mycelial and its aflatoxins production.
\end{abstract}

Copy Right, IJAR, 2017,. All rights reserved.

\section{Introduction:-}

Aspergillus parasiticus is a pathogenic fungus and many agricultural products are susceptible to infection of this mold. It affects mainly corn, peanuts, cotton seeds, tree nuts, etc (Mishra and Dubey, 1994). A. parasiticus produces aflatoxins that are known as carcinogenic, mutagenic, toxigenic and teratogenic in nature (Patten, 1981; Kumar et al., 2017a). Aflatoxins are considered as "Class 1 Human Carcinogen" by the International Agency for Research on Cancer (IARC) (Williams et al., 2004). Aflatoxins alter the root elongation, seedling growth, chlorophyll synthesis and seed germination (Jones et al., 1980). Tropical and subtropical countries are facing the problem of A. parasiticus 
as well as aflatoxins contamination most commonly due to their hot and humid climatic conditions. These climatic conditions are favourable for fungal growth and aflatoxins production (Kumar et al., 2017b). Some time food items are destroyed by oxidative stress due to free radical generation. The free radicals damage many cellular molecules such as nucleic acid, proteins and lipids (Prakash et al., 2015). Aflatoxins production, oxidative stress and free radical generation are directly proportional to each other (Jayashree and Subramanyam, 2000). Contamination of $A$. parasiticus and aflatoxins in cereal crops are a matter of serious concern around the world, and there is an urgent need to solve this problem.

Many synthetic food preservatives are used to prevent the contamination of fungus and mycotoxins, but these preservatives some time show harmful effects in human life. Synthetic food preservatives such as hexachlorobenzene (HCB) cause prophyria or poisoning in human (Jones et al., 1980). Other preservatives like captan, captafol and folpet cause irritation in skin, dermal sensitization and many respiratory problems (Royce et al., 1993; Vllaplana and Romaguera, 1993). It has been reported that synthetic preservatives like formaldehyde, nitrates, sorbates, butylatedhydroxyanisole and butylatedhydroxytoulene give the symptoms of hypersensitivity, hyperactivity, allergy, cancer and asthma (Anand and Sati, 2013).

Plants contain many types of secondary metabolites, which possess anti-fungal and anti-bacterial properties (Sharma and Sharma, 2012). Extracts of many plants showed antifungal properties against the growth of Aspergillus species (Thanaboripat et al., 2004; Krishnamurthy and Shashikala, 2006). Present study was designed to reveal the antifungal and anti-aflatoxigenic properties of the acetonic extract of Maize leaves against the infection A. parasiticus and aflatoxins production.

\section{Materials and Methods:-}

\section{Pathogenic organism used:-}

The toxigenic strain of A. parasiticus was procured from Department of Food Science \& Technology, Pondicherry University, Pondicherry, India. The culture was revived and maintained on fresh Czapek-Dox Agar (CDA) medium. The CDA culture plates were incubated for next 10 days at $28^{\circ} \mathrm{C}$ to ensure purity and viability.

\section{Preparation of acetonic extract:-}

Fresh leaves of maize (Malviya Hybrid Makka) were collected from agricultural regions of Dr. Rajendra Prasad Central Agriculture University at Pusa, in Samastipur district and kept in sterilized collecting polybag. These maize leaves were properly cleaned with running tap water followed by distilled water trice. Thereafter, leaves were dried in an oven for 72 hours. The leaves were crushed entirely by using mortar and pestle. About 60 grams of crushed leaves were weighed, and kept back into a sterilized conical flask. $300 \mathrm{ml}$ of acetone was added into the flask and left for 72 hours. Afterword, the solution was filtered through Whatman filter paper no. 1, and filtrate was collected into a flat bottom dish. Evaporation of the acetonic extract was performed at standard room temperature till dryness. The dry residue was again dissolved in small amount of acetone and water in the ratio of 50:50 (v/v), and kept at $4^{\circ} \mathrm{C}$ for the experimental work.

\section{Antifungal activity:-}

Agar plate diffusion method was employed to analyze the antifungal activity of the acetonic extract (Kumar, 2017). Different acetonic extract concentrations $(50 \mu \mathrm{l}, 100 \mu \mathrm{l}, 150 \mu \mathrm{l}, 200 \mu \mathrm{l}$ and $250 \mu \mathrm{l} / \mathrm{ml})$ were added into $20 \mathrm{ml}$ of molten CzapekDox Agar (CDA) medium in different Petri plates. Freshly prepared fungal disc (5 mm diameter) of $A$. parasiticus was spotted at the centre of each petri plate containing different concentrations of the acetonic extract. One Petri plate had taken as control, containing only $20 \mathrm{ml}$ of CDA medium and a fungal disc ( $5 \mathrm{~mm} \operatorname{diameter}$ ) of $A$. parasiticus. In next step, all petri plates were incubated at $28 \pm 2^{\circ} \mathrm{C}$ for next 10 days under controlled condition. After the incubation period, the mycelial development of the A. parasiticus was measured in diameter (in $\mathrm{cm}$ ) on the medium of each petri plate. Percentage of inhibition of the growth of the A. parasiticus was calculated by the following formula:

$$
\begin{gathered}
\text { Percentage of inhibition } \\
\text { of growth of test fungi }
\end{gathered}=\frac{\mathrm{DC}-\mathrm{DI}}{\mathrm{DC}} \times 100
$$

Where, $\mathrm{DC}=$ Average increase in mycelial growth in the control sample. 
DT $=$ Average increase in mycelial growth of the test sample.

Inhibition of aflatoxins production:-

To analyze the anti-aflatoxigenic properties of acetonic extract from Maize leaves, Czapek Dox Broth (CDB) medium was arranged. The sterilized fresh CDB media were poured into different conical flasks $(25 \mathrm{ml})$. The requisite amount of acetonic extract of different concentrations $(50 \mu \mathrm{l} / \mathrm{ml}, 100 \mu 1 / \mathrm{ml}, 150 \mu 1 / \mathrm{ml}, 200 \mu 1 / \mathrm{ml}$ and $250 \mu \mathrm{l} / \mathrm{ml}$ ) was added into each flask containing CDB medium. The fungal discs of $5 \mathrm{~mm}$ diameter were inoculated into each flask containing different concentrations of the acetonic extract. A flask containing only $25 \mathrm{ml}$ of CDB medium and a fungal disc ( $5 \mathrm{~mm}$ diameter) was used as control. Subsequently, all flasks were incubated at $28 \pm 2{ }^{\circ} \mathrm{C}$ for 10 days. After 10 days, the mycelium of A. parasiticus of each flask was filtered through Whatman filter paper no. 1. All the filtered mycelium of $A$. parasiticus was autoclaved to kill the spore pathogenicity. Then, the fungal mycelium were dehydrated entirely in an oven (at $80^{\circ} \mathrm{C}$ ) and weighed. The dried remnants were extracted by using $20 \mathrm{ml}$ chloroform, and chloroform extract was stored at room temperature to evaporate till complete dryness. Again, $1 \mathrm{ml}$ of chloroform was added into residue. $60 \mu \mathrm{l}$ of the chloroform extract was loaded on the thin layer chromatography (TLC) plates following the method of Turner and his colleagues (Turner et al., 2009) for confirmation of aflatoxin presence. Solvent system for TLC plate was prepared by the mixture of chloroform and acetone in the ratio of 9: $1(\mathrm{v} / \mathrm{v})$. After running the test sample, the TLC plate was dried and then transferred into a UV transilluminator $(360 \mathrm{~nm})$ to authenticate the presence of aflatoxins. The blue and green colour bands were observed on TLC plate under UV transilluminator. The blue and green colour bands indicated the presence of aflatoxins in the mold. All bands were scratched from the TLC plate, and dissolved in $5 \mathrm{ml}$ methanol followed by centrifugation at $3000 \mathrm{rpm}$ for 5 minutes. Absorbance of supernatant was noticed at $360 \mathrm{~nm}$, and the quantification of aflatoxins was done by using following formula:

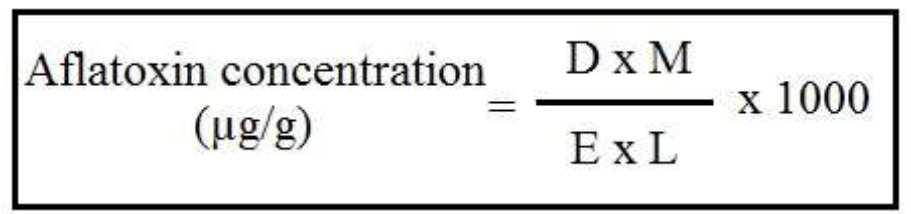

Where, $\mathrm{D}=$ Absorbance, $\mathrm{E}=$ Molar extinction coefficient of aflatoxins, $\mathrm{M}=$ molecular weight of aflatoxins, $\mathrm{L}=$ Path length.

\section{Phytochemical Screening:-}

Test for different types of phytoconstituents such as proteins, carbohydrates, terpenes and flavonoids were carried out of the acetonic extract of Maize leaves according to the method of Harbone (Harborne, 1993).

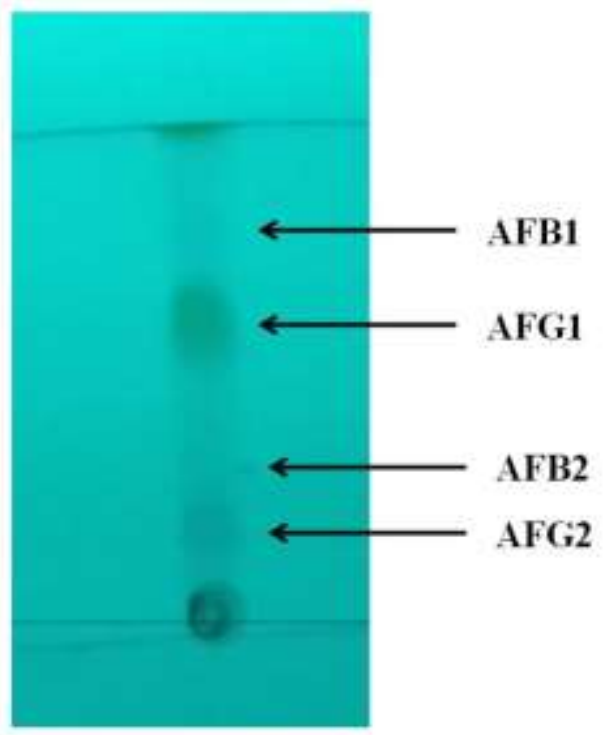

Fig1:-TLC plate of the extract untreated sample is showing the bands of aflatoxins 
Fig2:-TLC plate of the extract treated sample is showing the sample is not showing any bands of aflatoxins.

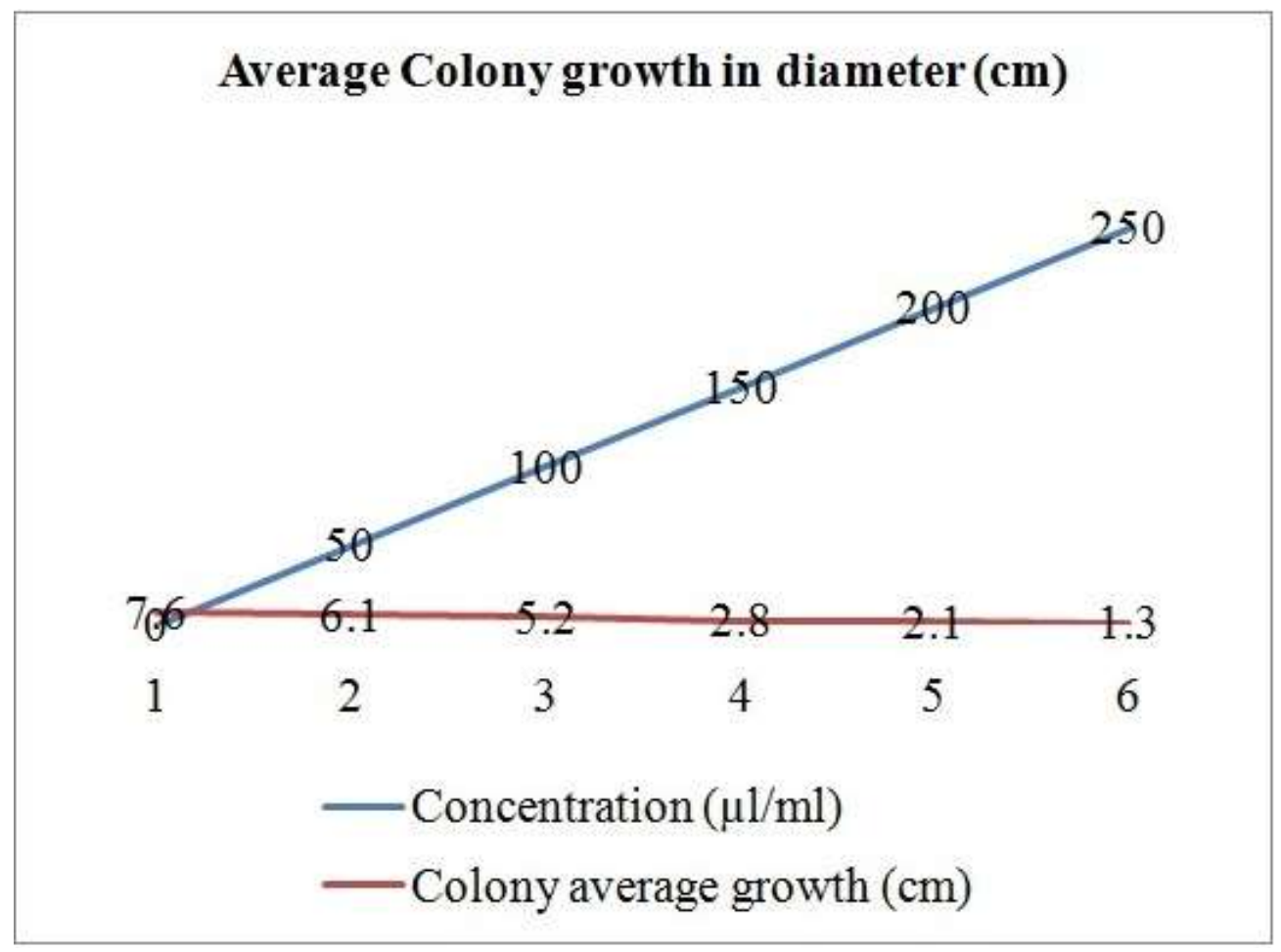

Graph1:- Average Mycelial Growth in Diameter (cm) 


\section{Mycelial growth inhibition of Aspergillus parasiticus growth (\%)}

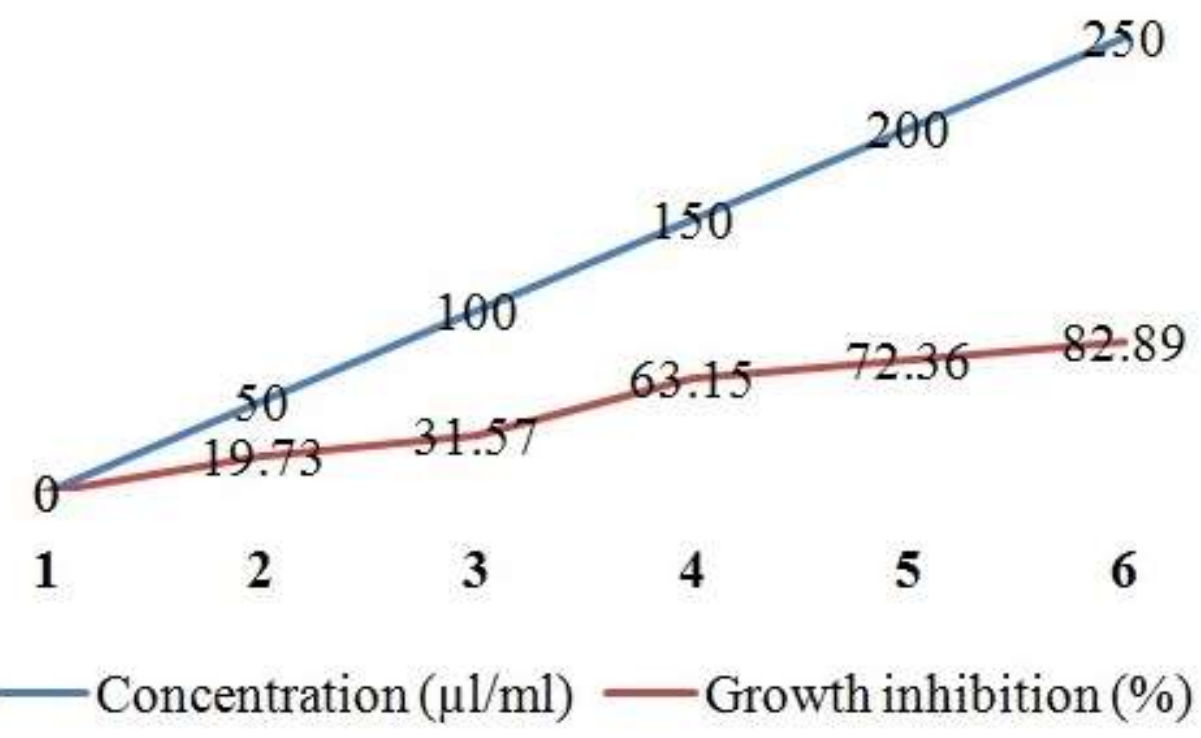

Graph2:- Inhibitory effect of the mycelial growth of A. parasiticusin percentage

\section{Decrease in Mycelial dry weight (gm) under effect of acetonic extract from Maize}

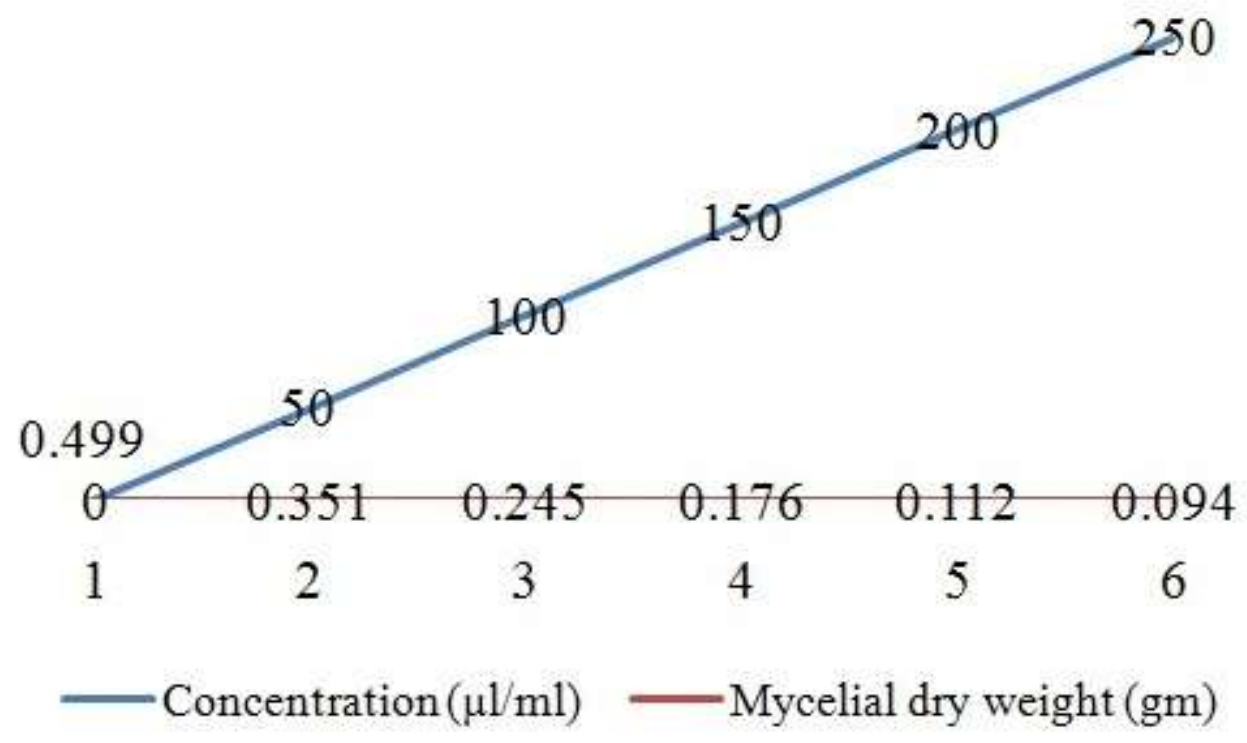

Graph3:- Effect of acetonic extract from Maize on mycelial dry cell mass (gm) 


\section{Decrease in aflatoxin production with incerase in acetonic extract in fungal culture media}

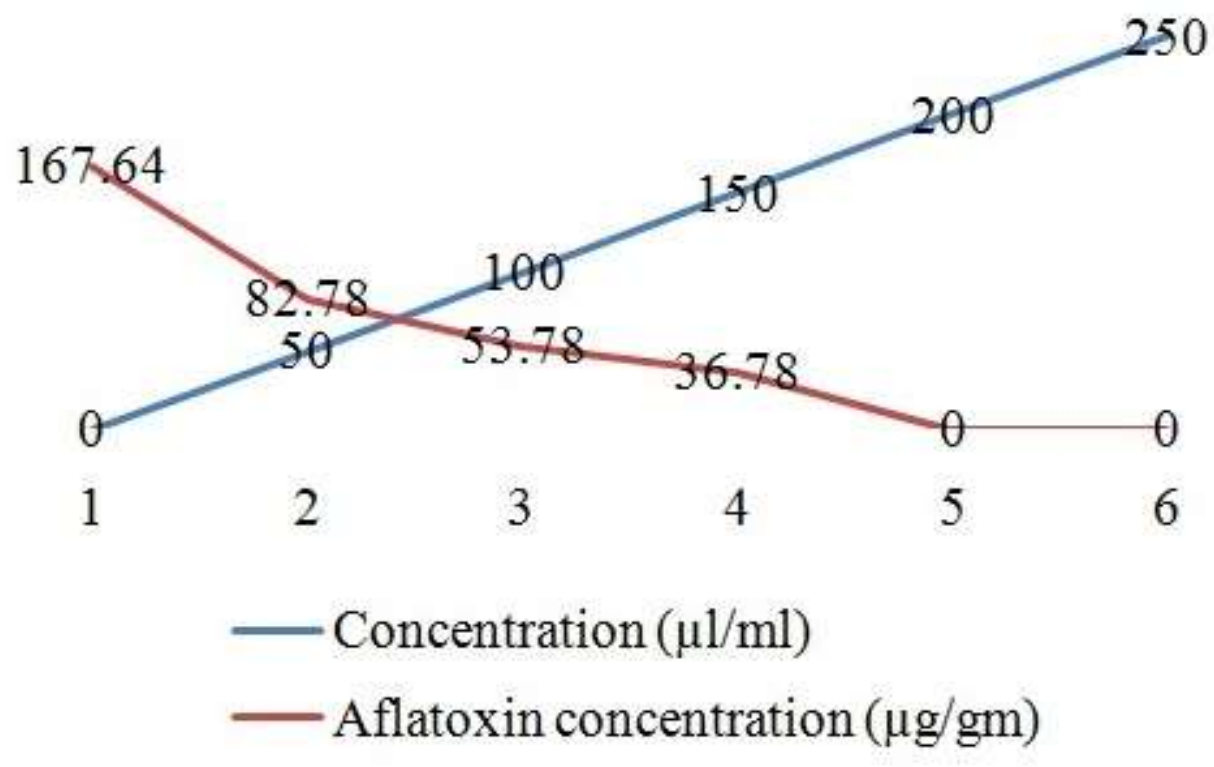

Graph4:- Inhibitory effect of Acetonic extract from Maize leaves on aflatoxin production.

\section{Result and Discussion:-}

Antifungal activity of the acetonic extract of Maize leaves on A. parasiticus has been showed in graph1. The result revealed that this extract has antifungal activity against the growth of $A$. parasiticus basically on dose depended manner. The inhibitory effect of the mycelial growth of A. parasiticus was shown in graph2. The extract untreated sample (control) showed well growth of A. parasiticus but the extract treated sample showed $82.89 \%$ inhibition of the growth of this mold at the concentration $250 \mu \mathrm{l} / \mathrm{ml}$.

Qualitative analysis of TLC plates under $360 \mathrm{~nm}$ UV light confirmed the presence of the four different types of aflatoxins such as B1, B2, G1 and G2. Quantitative studies revealed that the quantity of aflatoxins B1 was higher than other aflatoxins (B2, G1, and G2). The acetonic extract untreated sample (control) showed the bands of aflatoxins B1, B2, G1 and G2 on TLC plate (Fig1), but the acetonic extract treated sample did not show the bands of any aflatoxins on TLC plate at the concentration of $200 \mu 1 / \mathrm{ml}$ (Fig2).

The graph3 is presenting the anti-aflatoxigenic effect of the acetonic extract of Maize leaves. The result of antiaflatoxigenic activity revealed that this extract has capacity to inhibit the aflatoxins synthesis by A. parasiticus. The graph4 presents that the extract showed $100 \%$ inhibition of aflatoxins production at the concentration of $200 \mu 1 / \mathrm{ml}$. The mycelium growth and aflatoxins production were analysed to decrease on increasing the concentration of the acetonic extract. It was also analysed that decrease in mycelial biomass leads to decrease in aflatoxins production. Therefore, mycelial growth must be controlled below the limit to arrest the synthesis of aflatoxins.

Qualitative phytochemical screening of the acetonic extract of Maize leaves showed the presence of proteins, carbohydrates, terpenes and flavoinds. It has been reported that flavonoids have potential to inhibit the production of aflatoxins(Mallozi et al., 1996; Patel et al., 2010). Flavonoids, singly or in combination with other phytochemical compounds might be responsible for the antifungal and anti-aflatoxigenic properties of the acetonic extract of Maize leaves. 


\section{Conclusion:-}

The above findings clearly indicate that acetonic extract of the Maize leaves has contains some essential organic compounds. These compounds possess inhibitory effect on the growth of A. parasiticus along with its aflatoxins production. This extract may be used as plant based preservative to save foodstuff and cereal crops from the harmful effects of A. parasiticus and aflatoxins.

\section{References:-}

1. Anand, S. and N. Sati (2013). "Artificial preservatives and their harmful effects: looking toward nature for safer alternatives." International Journal of Pharmaceutical Sciences and Research. 4(7): 2496.

2. Harborne, J. B. ( 1993). "Phytochemistry." 89-131.

3. Jayashree, T. and C. Subramanyam (2000). "Oxidative stress as a prerequisite for aflatoxin production by Aspergillus parasiticus." Free Radical Biology and Medicine. 29(10): 981-985.

4. Jones, H., J. Chancey, W. Morton, W. Dashek and G. Llewellyn (1980). "Toxic responses of germinating pollen and soybeans to aflatoxins." Mycopathologia. 72(2): 67-73.

5. Krishnamurthy, Y. and J. Shashikala (2006). "Inhibition of aflatoxin B1 production of Aspergillus flavus, isolated from soybean seeds by certain natural plant products." Letters in applied microbiology. 43(5): 469-474.

6. Kumar H., K. M., Kumar M., Kumar B., Bharti S., Kumar, P., Kumar, J. (2017). "Effect of Acetone Extract of Zea Mays L. Leaves on the growth of Aspergillus flavus and Aflatoxin production." International Journal of Advanced Research. 5(8): 1667-1671.

7. Kumar, M., S. Rana, H. Kumar, J. Kumar, R. Mansuri and G. Chandra Sahoo (2017a). "Inhibition of Product Template (PT) Domain of Aflatoxin Producing Polyketide Synthase Enzyme of Aspergillus parasiticus." Letters in Drug Design \& Discovery. 14(7): 811-818.

8. Kumar, M., S. Rana, H. Kumar, P. Kumar, M. R. Dikhit, R. Mansuri, J. Kumar and G. C. Sahoo (2017b). "Computational, structural and functional aspects of hypothetical protein of Aspergillus flavus Pheromone Receptor Pre-A (PRP-A)." Journal of Applied Pharmaceutical Science. Vol 7(07): 089-097.

9. Mallozi, M. A., B. Correa, M. Haraguchi and F. Brignani Neto (1996). "Effect of flavonoids on Aspergillus flavus growth and aflatoxin production." Rev. microbiol 27(3): 161-165.

10. Mishra, A. and N. Dubey (1994). "Evaluation of some essential oils for their toxicity against fungi causing deterioration of stored food commodities." Applied and environmental microbiology. 60(4): 1101-1105.

11. Patel, J., B. Gami and K. Patel (2010). "Evaluation of in vitro schizonticidal properties of acetone extract of some Indian medicinal plants." Advances in Biological Research. 4(5): 253-258.

12. Patten, R. C. (1981). "Aflatoxins and disease." The American journal of tropical medicine and hygiene. 30(2): 422-425.

13. Prakash, B., P. K. Mishra, A. Kedia, A. K. Dwivedy and N. Dubey (2015). "Efficacy of Some Essential Oil Components as Food Preservatives Against Food Contaminating Molds, Aflatoxin B1 Production and Free Radical Generation." Journal of Food Quality. 38(4): 231-239.

14. Royce, S., P. Wald, D. Sheppard and J. Balmes (1993). "Occupational asthma in a pesticides manufacturing worker." Chest. 103(1): 295-296.

15. Sharma, A. and K. Sharma (2012). "Protection of maize by storage fungi and aflatoxin production using botanicals."

16. Thanaboripat, D., N. Mongkontanawut, Y. Suvathi and V. Ruangrattametee (2004). "Inhibition of aflatoxin production and growth of Aspergillus flavus by citronella oil." KMITL Science Journal. 4(1): 1-8.

17. Turner, N. W., S. Subrahmanyam and S. A. Piletsky (2009). "Analytical methods for determination of mycotoxins: a review." Analytica chimica acta. 632(2): 168-180.

18. Vllaplana, J. and C. Romaguera (1993). "Captan, a rare contact sensitizer in hairdressing." Contact dermatitis. 29(2): 107-107.

19. Williams, J. H., T. D. Phillips, P. E. Jolly, J. K. Stiles, C. M. Jolly and D. Aggarwal (2004). "Human aflatoxicosis in developing countries: a review of toxicology, exposure, potential health consequences, and interventions." The American journal of clinical nutrition. 80(5): 1106-1122. 